Title

Measuring motivation to learn Chinese and English through self-reported feelings and behaviours

Author(s)

Soh Kay Cheng

Source

Singapore Journal of Education, 13(1), 88-94

Published by Institute of Education (Singapore)

This document may be used for private study or research purpose only. This document or any part of it may not be duplicated and/or distributed without permission of the copyright owner.

The Singapore Copyright Act applies to the use of this document. 


\title{
Measuring Motivation to Learn Chinese and English Through Self-Reported Feelings and Behaviours
}

\author{
Soh Kay Cheng
}

\begin{abstract}
The socio-educational approach to measuring language motivation has its focus on social attitude rather than language-relevant feelings and behaviours in the classroom context. The development of two scales for measuring elementary students' motivation to learn Chinese and English reported here is an exploration of a psychology-based approach which may be more meaningful to language teachers. The scales share common items and cover both affective and behavioural aspects of language learning. Very high internal consistency was found for both scales. Discriminant validity was established with reference to student backgrounds, including overall academic performance, gender, language examination grade, home language, and self-evaluation of language ability.
\end{abstract}

Descriptors: Language motivation, bilingualism, measurement.

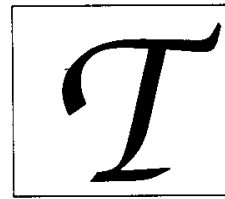

\section{Introduction}

eachers know well that students who are motivated to learn pay more attention and put in more effort and these make teaching more rewarding with better pupil behaviour in class and better achievement subsequently. This is true of any subject in the school curriculum and is, of course, true of language instruction. The causal effect of motivation on language learning is most emphatically pronounced by Gardner (1985, p 85), "The prime determining factor in language learning success is motivation." Even though Carroll did not include a motivation measure in the MLAT (Carroll \& Sapon, 1959), as did Pimsleur (1966) in his foreign language aptitude inventory, Carroll (1981, p 84), however, takes motivation for granted when defining language aptitude, thus,

the individual may be thought of as possessing some current state of capability of learning that task - if the individual is motivated, and has the opportunity of doing so. (Emphasis added)
Taking the earlier research on language motivation (Gardner \& Lambert, 1972) further, Gardner (1980) expanded the concept of language attitude/motivation index (AMI) to include three components: integrativeness, attitudes toward the learning situation, and motivation. AMI, while relatively independent of aptitude as measured by MLAT which correlates as expected with language grade, was found to be persistently correlated with French achievement for grades 7-11 students across several school areas. It is of note that, the first component of $\mathrm{AMI}$, integrativeness, is akin to the integrative motivation of the earlier conception (Gardner \& Lambert, 1972), whereas the other two components of AMI, attitude and motivation, have greater classroom relevance since they, for instance, pertain to affective reactions toward the course and the teacher and effort expended toward learning the language. Notwithstanding the debate on the validity of the socio-educational theory ( $\mathrm{Au}$, 1988; Gardner, 1988), there is no denying the importance of affect in language learning. 
The Lambert-Gardner approach to language motivation is social-psychological in orientation and concerns itself almost exclusively with social attitudes toward second-language acquisition and second-language community. While the educational and social significance of such attitudes are important in their own rights, the lack of this approach to language motivation in direct classroom relevance and immediate pedagogical implication is not to be denied. The need for a more practitioner oriented and psychology based approach to language motivation, which has a closer link with what the teacher does in terms of pedagogy and what the students do as classroom activities for and about the language to be learned, has recently been voiced by Crookes and Schmidt (1991) when they describe succinctly the concern of motivation among practising teachers:

It is probably fair to say that teachers would describe a student as motivated if he or she becomes productively engaged in learning tasks, and sustains that engagement, without the need for continual encouragement or direction.

Moreover, for obvious reasons, much of the research on language motivation has been done with more mature students of high schools and colleges than with younger children in elementary schools, although it is a widely accepted notion that to be good in a language requires one to start young. Thus, for measuring language motivation of younger school children, scales that are more relevant to their experience and hence better understood by them would be useful for research and, ultimately, instructional purposes. Moreover, while the importance of the affective or attitudinal aspect of language motivation is well-recognised, the behavioural aspect deserves as much attention if the measures are to be of practical value to classroom teachers who may then guide the students in changing their language-relevant behaviours, which understandably is more amenable to change than language-relevant attitude.

In view of the need for a motivation measure to be anchored in the classroom context and to take into account both students' affects and behaviours, Hart's (1981) conception of a motivational and an informational components is relevant. She attempted at developing a factor scale of motivation for classroom learning, though not specific to language learning. The five dimensions defined are: preference for challenge versus preference for easy work, curiosity and interest versus teacher approval, independent mastery attempts versus dependence on the teacher, independent judgement versus reliance on the teacher's judgement, and internal versus external criteria for success/failure. Hart's study shows that five dimensions can be established, where the first three are motivational in nature while the last two are cognitive-information. When considering the possible structure of the language motivation scales to be developed, it was felt that Hart's dimensions would provide a conceptual scaffolding for the scales, with slight modification by expanding the sixth dimension, criteria, into two for social motivation and selfmotivation.

In Singapore, the bilingual education policy requires Chinese-Singaporean children to learn Chinese (Mandarin) and English right from first grade. As would be expected, related to variation in language environment at home and through the family's network, some students do well in one but not the other language, while only a small proportion is expected to be able to, and actually show, mastery of both languages; it has been estimated that only about $10 \%$ of elementary school students are able to attain balanced bilingualism, that is, in Singapore terminology, "to offer English and the mother tongue at first language level" (Yip et al., 1991). In Singapore, as in elsewhere, attitude/motivation is frequently cited as an important contributing factor to explain success or the lack of it in language learning. Thus, the students' language motivation deserve research effort and instruction attention. This implied of course, the need for valid, reliable and user- (teacher-) friendly measuring devices.

Incidentally, maybe of side interest, most language motivation research deals with two related languages (eg English and French, Spanish and English, etc.). The languages of concern here are from two distinctly different 
linguistic families, and hence it would be interesting to see if the structures of language motivation in this situation are similar.

English was considered a more suitable language for presenting the scales to students for their response, instead of using both languages for their respective versions. This decision was taken because the students in general may not have adequate reading ability in Chinese to understand the items if they were in Chinese. Moreover, students with low motivation to learn Chinese language are most likely those who are weak in this language but strong in English. Furthermore, when the scale is ultimately used for evaluation, classroombased research and counselling purposes, information gathering may be undertaken not by the Chinese language teacher but the form teacher, the departmental head or even the principal who may find an English version more meaningful and convenient to use.

With the above considerations, a scale was designed which has common items that can be used for measuring motivation to learn Chinese (Mandarin) and English after the necessary adjustment for the referenced object (the language). This article reports the attempt to develop such a scale.

\section{Chinese Language Motivation Scale (CLMOTS)}

\section{The Scale}

The draft version of the CLMOTS consists of 30 items. The items depict feelings the students may experience and behaviours they may display in connection with the learning of Chinese, especially in the context of the classroom. Five items were intended for each of the six aspects of language motivation mentioned earlier, following largely Hart's (1981) conceptualisation: challenge, curiosity/interest, mastery, judgement, social motivation and self-motivation. When considering motivation at the classroom level, crookes and Schmidt (1991) highlight preliminaries, activities, feedback, self- evaluations, and material as specific components of language motivation. These were taken into account in developing the scale for the present study. The items were presented with a fourpoint scale indicating the degree of applicability of the statements to the pupil, ranging from Always true, True, Not true and Always not true. When the draft CLMOTS was administered, the teacher read the test instructions and the items aloud while the students followed silently and responded accordingly. Data collection was carried out in the early part of the school year.

\section{The Sample}

The trial of the CLMOTS involved four classes of Primary Five students from a school with a strong Chinese tradition located in a densely populated public housing estate. After exclusion of scripts with incomplete data, there were 123 students whose responses were analysed for CLMOTS. These students came from classes of a wide range of overall academic standing with slight preponderance from the higher end $(55.1 \%)$. However, this distribution does not deviate significantly from equal distribution of high (classes $\mathrm{A}$ and $\mathrm{C}$ ) and low (classes $\mathrm{E}$ and $\mathrm{F}$ ) achievers (chi-square 1.829, df 1, p>0.05). There is also a slight preponderance of females $(54.5 \%)$ but this does not deviate significantly from an equal distribution of sexes (chi-square 0.984, df $1, p>0 \cdot 05)$. These students' results for the schoolbased Chinese language examination for the year prior to data collection was somewhat on the high side, with $44.7 \%$ in the high band, $43.1 \%$ in the middle band, and only $12.2 \%$ in the lowest band. Considering the location of the school and the Chinese language grades of the students involved, it was not unexpected that Mandarin was the home language of the great majority $(78.9 \%)$. This was further reflected by the students' self-evaluation of Chinese language ability, with more than half $(53.7 \%)$ rating themselves as being good or very good in the language, another one-third $(33.3 \%$ ) rating themselves as being average, and only a small proportion $(1.30 \%$ ) giving low self-ratings (Not so good and very poor). 


\section{Factor Analyses}

The 123 students' responses to the 30 -item trial version of the CLMOTS were submitted for a principal components analysis. The analysis yielded eight unrotated orthogonal factors explaining $67.07 \%$ total variance. The first factor explained $34.85 \%$ and the remaining seven factors explaining from 7.045 to $3.47 \%$. A scree plot shows the drastic drop of proportion of explained variance after the first factor and, thus, suggest its retention and the exclusion of the remaining factors from subsequent analysis. The first factor, 12 items with the highest loadings varying from 0.61 to 0.75 , were selected for further analysis.

The second run yielded only one factor formed by all 12 retained items, with loading ranging from 0.67 to 0.75 and $52.03 \%$ total variance was accounted for. The items and loadings are shown in Table 1. It can be seen that the items cover all six aspects of the original conceptualisation, though numbers of items varied, thus: Challenge 1, Curiosity/interest 1, Mastery 4, Judgement 3, Social Motivation 1, and Self-Motivation 2. Although the scale formed by these 12 items measure the students' motivation to learn Chinese language in a broad and general manner, there is a strong element of making a conscious effort to master the language and keen concern for improving the ability in the Chinese language.

\section{Reliability}

The reliability of the final version of the 12 -item CLMOTS was evaluated for its internal consistency using Cronbach's alpha coefficients. These were estimated for different groups by sex, examination grade, self-evaluation and for the students as a whole. As Table 2 shows, CLMOTS has high reliability coefficients varying from 0.86 to 0.92 which indicate high internal consistence for various groupings. For the sample as a whole, the CLMOTS has a Cronbach alpha of 0.91 .

\section{Validity}

The validity of the CLMOTS was evaluated by comparing students on their motivation score with reference to the background variables. First, the motivation means decreased with the general academic levels of the classes, with Class A scoring $40 \cdot 30$, Class C 38.92, Class E 38.09, and Class $F$ 30.78. One way ANOVA show an overall difference among the groups ( $F=13.94$, df $3, p<0.01$ ). However, Duncan's test shows classes $C$ and $E$ to be not significantly different from Class $A$, indicating that the CLMOTS was more effective in discriminating between low achievers and those average and higher achievers. Secondly, the mean of 34.84 for males is significantly lower than that of 38.85 for females ( $F=9.49$, df $1, p<0.01)$; this indicates that girls were more highly motivated than boys in learning the Chinese language. The third comparison was made between students with high and low Chinese examination grades. As would be expected, students whose last Chinese examination results placed them in Bands 1 and 2 were motivated when compared with their peers in Bands 3 and 4 . The motivation means of 39.23 and 34.68 differ significantly $(F=12.74$, df $1, p<0.01$ ).

The fourth significant difference was found between those who always speak Mandarin at home $(37.81)$ and those who do not. The motivation means of 37.81 and 34.08 , for the two groups respectively, are significantly different $(F=5 \cdot 36$, df $1, p<0.05)$. This suggests the importance of home support in motivating students to learn the Chinese language. Fifthly, students who evaluated their own Chinese language ability most favourably (Very good and Good) obtained a motivation mean of 38.70 . This differed significantly from the mean of 36.09 of those whose self-evaluation was less favourable (Average, Not so good and Very poor). Again, there is a significant difference between these means $(F=7.59$, df $1, p<0.01)$. Thus, students who saw themselves in better light were more strongly motivated to learn Chinese, as would be expected. 


\section{English Language Motivation Scale (ELMOTS)}

\section{The Scale}

The draft version of the ELMOTS consists of 30 items which are exactly the same as those of the CLMOTS, except that the word "Chinese" was replaced by "English". It will be recalled that the items depict students' feelings and behaviour relevant to the language, with five items for each of the six aspects of motivation. The ELMOTS was administered together with the CLMOTS in the early part of the school year (February). The teacher read the test instructions and the items aloud for the students to follow.

\section{The Sample}

The same groups of students who completed the CLMOTS were administered the ELMOTS. After eliminating scripts with incomplete data, 138 were retained. Their school-based English language examination results for the past year were, not unexpectedly, somewhat lower than those for their Chinese language examination, with $40.6 \%$ in the high band, $35.5 \%$ in the middle band, and $23.9 \%$ in the lowest band. Considering these students' home background, it was not unexpected that English was the home language of only $39.1 \%$. Hence, less than half $(44.2 \%)$ gave favourable self-evaluation rating themselves good or very good in the English language, two-fifths (39.9\%) rated themselves as being average, and one-sixth (15.9\%) rated themselves as Not so good and Very poor. The slight preponderance of students from the lowerend $(54.4 \%)$ classes is not significantly different from an equal distribution (chi-square 1.043, df $a, p>0.05$ ) and so was the slight preponderance of female students $(53.6 \%$, chi-square 0.725 , df $1, p>0.05$ ).

\section{Factor Analyses}

As was done for the CLMOTS, the 138 students $^{\prime}$ responses to the ELMOTS were submitted for a principal components analysis which yielded eight unrotated orthogonal factors explaining $63.11 \%$ total variance, with the first factor explaining $31.6 \%$ and the remaining seven factors explaining from $5.92 \%$ to $3.48 \%$. When the factor pattern of the ELMOTS was compared with that of the CLMOTS, there are 11 items common to both scales among the 12 highestloading items. The exception in the ELMOTS is item number 10 ("When I see English words on signboards, I like to know how to read them and what they mean.") with a loading of 0.62 when compared with item number 30 ("I study for English tests even before the teacher tells us to do so.") with a loading of $0 \cdot 61$. Given such a minute difference, it was decided to include item number 30 in the ELMOTS in its final version so that the scales for the two languages can have identical wordings except, of course, the language each refers to. A second run of the 12 selected items yielded only one factor with loading ranging from 0.62 to 0.85 and $51.06 \%$ total variance was accounted for (Table 1 ).

\section{Reliability}

As Table 2 shows, the 11 item final version of ELMOTS has high reliability coefficients varying from 0.89 to 0.92 which indicate high internal consistency for various groupings. A Cronbach alpha of 0.91 was obtained for the ELMOTS for the sample as a whole.

\section{Validity}

The ELMOTS was evaluated for its validity through comparing students' motivation scores derived from their responses to the 11 -item scale with reference to their background variables. First of all, the motivation means varied with the general academic levels of the classes: Class A 41.31 , Class C 39.64 , Class E 38.90 and Class $F$ 28.78. One way ANOVA shows the differences to be significant, overall ( $F=29.80, d f 3, p<0.01)$. However, Duncan's test shows Classes $C$ and $E$ to not be significantly different from Class $A$. Thus, ELMOTS was more effective in discriminating between low achievers and the average and higher achievers. Next, the motivation means of males (34.19) and females $(39.02)$ are significantly different $(F=9.49$, df 1 , $\mathrm{p}<0.01$ ); this indicates that girls were more highly motivated than boys in learning English. 
Thirdly, students with high English examination grades (Bands 1 and 2) obtained a motivation mean of 39.40 whereas those with medium and low grades (in bands 3 and 4 ) obtained a mean of 36.35 . The means differ significantly $(F=9.67$, $d f$ $1, \mathrm{p}<0.01)$.

A fourth significant difference $(F=5 \cdot 36, d f 1$, $\mathrm{p}<0.05$ ) in motivation means was found between those who always speak English at home (39.74) and those who do not (35.04). This again suggest

Table 1: Factor Loadings the importance of home support in motivating students to learn English. Fifthly, students who evaluated their own English language ability most favourably (Very good) had a motivation mean of 39.46 whereas those whose selfevaluation was not favourable (Not so good and Very poor) had a mean of 34.83 . These means differed significantly $(F=12.41$, df $1, p<0.01)$, indicating that students with stronger motivation to learn English were those who evaluated themselves more favourably.

\begin{tabular}{|c|c|c|c|}
\hline \multicolumn{2}{|c|}{ ITEMS } & \multirow{2}{*}{$\frac{\text { CLMOTS }}{0.75}$} & \multirow{2}{*}{$\frac{\text { ELMOTS }}{0.62}$} \\
\hline 1 & $\begin{array}{l}\text { Even if my Chinese/English homework is } \\
\text { difficult, I still enjoy doing it. }\end{array}$ & & \\
\hline 2 & $\begin{array}{l}\text { When the teacher tells us something about } \\
\text { Chinese/English words, I listen carefully }\end{array}$ & 0.71 & 0.73 \\
\hline 3 & $\begin{array}{l}\text { I listen carefully in Chinese/English class, } \\
\text { because I do not want to miss anything the } \\
\text { teacher is teaching us. }\end{array}$ & 0.70 & 0.85 \\
\hline 4 & $\begin{array}{l}\text { Some Chinese/English words are difficult to } \\
\text { write but I keep trying until I can write them } \\
\text { correctly. }\end{array}$ & 0.72 & 0.76 \\
\hline 5 & $\begin{array}{l}\text { If a Chinese/English word is difficult to read, } \\
\text { I'll practise so that I can 'say' it correctly. }\end{array}$ & 0.77 & 0.71 \\
\hline 6 & $\begin{array}{l}\text { If I have made mistakes in my Chinese/English } \\
\text { homework, I like to do corrections. }\end{array}$ & 0.71 & 0.64 \\
\hline 7 & $\begin{array}{l}\text { When my Chinese/English teacher tells me } \\
\text { about my mistakes, I listen carefully. }\end{array}$ & 0.75 & 0.83 \\
\hline 8 & $\begin{array}{l}\text { I like my Chinese/English teacher talking to me } \\
\text { about my homework. }\end{array}$ & 0.67 & 0.77 \\
\hline 9 & $\begin{array}{l}\text { I study hard to get good marks for my Chinese/ } \\
\text { English homework. }\end{array}$ & 0.73 & 0.66 \\
\hline 10 & I like to help my classmates learn Chinese/English. & 0.71 & 0.66 \\
\hline \multirow[t]{2}{*}{11} & $\begin{array}{l}\text { I study for Chinese/English tests even before the } \\
\text { teacher tells us to do so. }\end{array}$ & 0.70 & 0.64 \\
\hline & $\%$ total variance explained & 52.03 & 51.06 \\
\hline
\end{tabular}

Table 2: Reliability Coefficients

\begin{tabular}{|lcc|}
\hline Groups & CLMOTS & ELMOTS \\
\hline Males & 0.90 & 0.89 \\
Females & 0.91 & 0.92 \\
High grades & 0.86 & 0.92 \\
Medium \& low grades & 0.92 & 0.90 \\
High self-evaluation & 0.90 & 0.92 \\
Low self-evaluation & 0.91 & 0.89 \\
All Students & 0.91 & 0.91 \\
\hline
\end{tabular}


The scales for measuring elementary students' motivation to learn Chinese and English, as reported here, share common items, and cover both the affective and behavioural aspects of language motivation in a bilingual schooling context. The two scales show a high degree of internal consistency and discriminant validity with reference to students' background variables including overall academic performance, gender, language examination grade, home language and self-evaluation of language ability. The scales are intentionally kept short so that they will be convenient to use for evaluation, classroom-based research and counselling.

The results seem to indicate that a psychology-based and pedagogy-oriented approach to the measurement of language motivation in the classroom is feasible and promises fruitful development. As for research into language motivation, this approach perhaps serves to complement the attitude-based, integrative-instrumental approach of earlier research carried out in a broader, social context outside the perimeters of the language classroom. Crookes and Schmidt (1991) propose as an item of research agenda "How is SL motivation to be measured or operationalised? Apply validity and reliability criteria to instruments and operationalisations" ( $p$ 498). The attempt made in the present study, by incorporating Hart's (1981) conception of classroom motivation and the specifics suggested by Crookes and Schmidt in a language learning situation, is just one possible answer to this call and, obviously, further research is warranted. Further work that could be considered is to ascertain the validity of the scales when used with students at higher as well as lower academic levels, since the development of the scales involved only grade five students. It would also be useful for both theoretical and practical purposes to check empirically on the predictive (as contrasted with the correlational) efficacy of the approach adopted here.

\section{REFERENCES}

Au, S.Y. (1988). A critical appraisal of Gardner's socio-psychological theory of second-language (L2) learning. Language Learning, 38 (1), 75-100.

Crookes, G. \& Schmidt, R.W. (1991). Motivation: reopening the research agenda. Language Learning, 41 (4), 469-512.

Carroll, J.B. (1981). Twenty-five years of research on foreign language aptitude. In K.C. Diller (Ed.), Individual Differences and Universals in Language Learning Aptitude, 83-118. Rowley, MA: Newsbury House.

Carroll, J.B. \& Sapon, S.M. (1959). Modern Language Aptitude Test, Form A. New York: The Psychological Corporation.

Gardner, R.C. (1980). On the validity of affective variables in second language acquisition: Conceptual, contextual, and statistical considerations. Language Learning, 30, 255-270.

Gardner, R.C. (1985). Social Psychological Aspects of Language Learning: The Role of Attitudes and Motivation. London: Edward Arnold.

Gardner, R.C. (1988). The socio-educational model of second language learning: assumptions, findings and issues. Language Learning, 38 (1), 101-126.

Gardner, R.C. \& Lambert, W.E. (1972). Attitudes and Motivation in Second-Language Learning. Rowley, Mass.: Newsbury House.

Hart, S. (1981). A new self-report scale of intrinsic versus extrinsic orientation in the classroom motivation and informational components. Developmental Psychology, 17(3), 300-312.

Pimsleur, P. (1966). Testing foreign language learning. In A. Valdman (Ed.) Trends in Language Teaching. New York: McGraw-Hill.

Yip, I.S.K. et al. (1991). Improving Primary School Education: Report of the Review Committee. Singapore: Ministry of Education. 